\title{
Capturing characteristics of the conceptual ideation process of master crafts persons to inform design education: a comparative study of rural craft practitioners in Indonesia and in the UK
}

\author{
Deny Willy Junaidy* \\ Interior Design Study Program, \\ School of Creative Industries, \\ Telkom University, \\ Jl. Telekomunikasi No. 1, Terusan Buah Batu, \\ Bandung 40257, Indonesia \\ Email: denywilly@tcis.telkomuniversity.ac.id \\ *Corresponding author
}

\author{
Jake Kaner \\ Furniture Research Group, \\ School of Design, Craft and Visual Arts, \\ Buckinghamshire New University, \\ Queen Alexandra Road, High Wycombe Bucks, HP11 2JZ, UK \\ Email: jake.kaner@bucks.ac.uk
}

\section{Florin loras}

Institute for Conservation, Sustainability and Innovation,

Buckinghamshire New University,

Queen Alexandra Road,

High Wycombe, Bucks HP11 2JZ, UK

Email: florin.ioras@bucks.ac.uk

\section{Yukari Nagai}

School of Knowledge Science,

Japan Advanced Institute of Science and Technology,

1-1 Asahidai, Nomi, 923-1292, Japan

Email: ynagai@jaist.ac.jp

\begin{abstract}
At the very early stage of idea generation, allegedly, a master craftsperson encounters cognitive dissonance to maintain beliefs/mindsets from various conceptual stimuli. We aim to capture the underlying form of cognition by examining the structure of thoughts collected from the subjective conceptualisation. A think-aloud protocol was employed to obtain verbalised thoughts of both Indonesian and UK master craftsmen. The keywords of verbalised thoughts were evaluated and extracted using a list of typical mindsets. The evaluated keywords were then analysed by means of a
\end{abstract}


conceptual network to reproduce a model of the individual's mental state. This study discovered that Indonesian master craftsmen's conceptualisation is greatly influenced by the strong typical mindsets of object-attribute that emphasise rationale and mastery, which stimulates a pragmatic viewpoint. Furthermore, UK master craftsmen's conceptualisation greatly considers strong typical mindsets of object-attribute that emphasise wisdom and passionate, which indicates a rigorous mind. This paper reveals that both pragmatic and rigorous mindsets can create potential or barriers for creative cognitive resources.

Keywords: conceptual ideation; creative cognition; craftsman; typical mindsets; Indonesia; UK.

Reference to this paper should be made as follows: Junaidy, D.W., Kaner, J., Ioras, F. and Nagai, Y. (2015) 'Capturing characteristics of the conceptual ideation process of master crafts persons to inform design education: a comparative study of rural craft practitioners in Indonesia and in the UK', J. Design Research, Vol. 13, No. 4, pp.395-423.

Biographical notes: Deny Willy Junaidy is a faculty member at the School of Creative Industries, Telkom University. He worked as a Research Assistant and received his $\mathrm{PhD}$ (best student award) from the School of Knowledge Science, Japan Advanced Institute of Science and Technology (JAIST). He was previously a research student at Kyushu University and a Visiting Researcher at the Furniture Research Group, Buckinghamshire New University, UK. His research area is knowledge creation process from the viewpoint of design.

Jake Kaner is a Professor at the National School of Furniture and leads the Furniture Research Group at Buckinghamshire New University, UK. He received his $\mathrm{PhD}$ from Brunel University in 2001. He has worked with furniture craft practitioners, industry, heritage organisations and universities in the UK and Europe. His research interests in pedagogic creativity generation are centred on design, craft and industry.

Florin Ioras is a Professor at Buckinghamshire New University, UK where he leads the Institute of Conservation, Sustainability and Innovation. He received his PhD from Brunel University in 2000. He has published extensively on the furniture industry in ASEAN countries. He has research interests in the sustainability of craft practitioners, SMEs, forestry and resource management in Europe and Africa.

Yukari Nagai is a Professor at the School of Knowledge Science, Professor of the Research Center for Innovative Lifestyle, and Director of the Design Creativity Research Unit at the Japan Advanced Institute of Science and Technology (JAIST). Currently, she is the Dean of the Graduate School of Knowledge Science. She received her PhDs from Chiba University, Japan in 2002 and University of Technology, Sydney in 2009. Her research areas of interest are design creativity, design knowledge, creative cognition, and social innovation. 


\section{Introduction}

Design and creativity is a relatively new subject in science as to date design and creativity research has borrowed theories from cognitive science and psychology (Adams and Atman, 1999; Gero, 1999; Kotzé et al., 2008). Design and creativity is a developing research area that has the potential to contribute to the foundations of our cognitive understanding. It is a challenge for the design creativity research community to reveal the true nature of the creative processes in design. Most studies in the field of creativity have focused on the role of conceptual stimulus freedom that leads to creative solutions rather than barriers (i.e., cognitive fixedness) and involving participants of people in general, i.e., students, engineers. Studies have designated the conservative or traditional viewpoint as mental constructs that can impede our ability to develop creative ideas, therefore people with a traditional viewpoint have never been investigated seriously (German and Barret, 2005; Martindale, 1995). Almost no attention has been given to examine the potentials hidden in these barriers (Jansson and Smith, 1991; Gero, 2011; Viswanathan and Linsey, 2012; Klamer, 2012). This paper aims to identify these mental constructs in master craftsman, which can inform design education to improve their creativity and range of design potential.

\subsection{Craftsmanship}

In Indonesia, a rural master craftsman (hereafter referred to as 'craftsman') is a traditional master craftsperson who resides in a rural area. In the UK, the non-metropolitan craftsman works in rural areas or small conurbations. Both have acquired special craft skills and gained expertise in his or her vernacular traditional crafts that have been passed down from one generation to another often through an apprenticeship system. Yanagi, a Japanese craftsman and philosopher, asserts a true craft is a non-individually-inspired 'high' art, which is widely known as folk craft, used in people's everyday lives, unpretentious, pure and simple created by craftsman, to distinguish it from the craft artist (Yanagi, 1949; Leach, 1972). Pye (1968) provides an improved definition of craftsmanship as 'workmanship of risk,' where risk represents a piece of work which could be unexpectedly defective during the working process, can be a result of any tools, such as chisel, hammer; or a result of improper treatment, where this risk can be advantageous, unique or even failure (Pye, 1968). This means either techniques or processes are considered conservative; however, it exceptionally offers unconventional process to be present. Despite a presumption that the craftsman thinks in a conventional manner he or she is often aware of being unconventional (Racz, 2009).

\subsection{Conceptual ideation of a craftsman}

Scholars of modern studies of craftsmanship recognise a crucial point that craftsmanship is a mastery of doing and making involving beliefs and conservatism. These aspects in many studies of craftsmanship are frequently discussed as a representation of technical processes and skills (Pye, 1968; Solmsen, 1963; Galey, 1981; Blair and Ramsay, 1999; Sennet, 2008). Sennett (2008) argues that a craftsman is know-how of 'mind', 'hand', between ideation and practical execution, which represents the special human condition of being engaged. To date this statement is the most pertinent definition which reflects the craftsman's conceptual ideation process (Sennet, 2008). Studies in contemporary 
crafts (Greenhalgh, 2002) show that this process is still evident even though the creations have transferred to new mediums such as three dimensional printing.

Conceptual ideation is an essential step in the design thinking process that involves interplay between cognitive and affective skills that leads to the resolution of recognised difficulties (Houtz and Patricola, 1999). Conceptual ideation is generating and developing new ideas where an idea is understood as a basic element of thought that can be either visual, concrete, or abstract (Jonson, 2005). The ideation state defines one's current location in the design space where one gets deeper insight, discovery and conflicts.

It is generally known that traditional people think in a conventional manner. Gero (2011) affirms that conventional ways of thinking is when one is trapped at a general fixation and has premature commitment. A premature commitment refers to when someone appears trapped to a particular set of design decisions that they are familiar with (Gero, 2011). With a high level of mastery, an individual like a craftsperson is often recognised for his/her traditional viewpoints that may be structured by prior knowledge and typical features contained in familiar categories (Finke, 1996). The recent study of Nagai and Junaidy (2013) demonstrated that the craftsmen's conceptualisation at the early stage of idea generation experiences a fixation that disables them from exploring the abstract realm which normally occurs at the early stage of idea generation. This explains that the craftsman's conceptualisation, seen at the early stage, has evidently occurred at the later stage of idea generation (Junaidy and Nagai, 2013).

\subsection{Rural craft industry}

It is probable that Indonesians adopted the carpentry skills from the Chinese and Sinhala (Srilanka) at European trading posts that spread out throughout Indonesia in the $18^{\text {th }}$ century. Furniture was widely made during the European presence in Indonesia to maintain a lifestyle simulating the West as well as being made to provide gifts to local rulers (Cai, 1993; Cookson and Ishimura, 2009; van Gompel et al., 2013). Over three and a half centuries of Dutch occupation, the woodworking-based industry evolved, especially in Java. Besides artisanal wood-carving skills, Indonesia is also known for its outstanding array of traditional crafts ranging from potteries, to batik fabric. In addition, Indonesia's forest land that comprises $60 \%$ of the country's land area makes it the third largest area of tropical rainforest in the world (UN-REDD Programme, 2009), which potentially provides strategic competitiveness allowing for a strong craft industry. However, owing to the strong influence of the colonial era no indigenous traditions developed. With little innovation in local industry the local people are accustomed to only copying or modifying (Wiyancoko, 2002).

Rural industries in the UK are broadly known as small industries to fulfil some local demand using locally found raw material. The finished products in these country districts were made using predominantly manual and traditional methods (Fitz Randolph et al., 1978). Rural industries are located mainly at forested uplands. Rural craft industries cover greenwood crafts, basket-making and blacksmithing. Chair-making in the Chiltern region is widely known as one of the important craft industries in the late 18th century which employed several thousand persons (Pihlens, 2014). The peak of the rural chair-making workshop began in the late 18th century. After 1890 it began rapidly to decrease along with the birth of the local industrial revolution and the rise of machining technology. Historically, the arts and crafts movement in England was one of the most influential styles that reinvigorated craft activities in response to industrial production 
and its consequent rationalisation of labour (Beattie, 2009). However, the decline in demand for craft products was inevitable, owing to technical obsolescence, changing fashions and manufacturers' abilities to produce cheaper ranges of furniture.

Rural craft industries in Indonesia and UK have strong historical backgrounds and at the same time encounter the same problems to sustain the business. In the case of Indonesia, with its high level of woodworking skills, being above average remains pointless as the ability for innovation and product development is still a major obstacle. In the UK the demand from consumers for modernity and quick production has hindered the growth of craftsmanship, which relies on traditional forms.

UK and Indonesia have a long history of furniture trading. In 1801, the British East India Company built the trading office in Indonesia. Both countries influenced each other through different approaches to seating and the use of unique local cane materials, as well as displaying a variety of craftsmanship skills. These examples of cultural exchange increase the need to more fully understand the cultural uniqueness of the mindsets and stimuli of the master craftsman. This informed comprehension will provide resources for the development of design training (nationwide governmental HRD program in developing countries) that focus on the enhancement of traditional craftsmen's cognitive resources to produce more desirable products.

\section{Methodology}

In order to understand the early stages of idea generation we investigated the characteristics of the conceptual ideation process of master craftsmen by examining the structure of thoughts collected from their subjective experiences (think-aloud protocol).

Think-aloud protocol has been used to study cognitive factors in a number of clinically relevant contexts, including depression and psychotherapy processes. The think-aloud procedure allow researchers to assess issues fundamental to cognitive behaviour therapy and psychopathology. Earlier think-aloud studies were widely used to reveal articulated thoughts at the cognitive assessment stage that has several advantages. Davison et. al. (1997) observed this through the experimental states recognising that it seemed promising as a versatile and adaptable method of cognitive assessment, especially when little is known of the cognitive terrain of interest. Recently, Georgiev et al. (2012) combined the think-aloud protocol with concept-network analysis to capture and analyse the in-depth impressions from or inner associative layer of humans' expressed impressions behind the surface impressions. Also, Junaidy and Nagai (2013) had conducted the similar method to capture in-depth cognitive levels related to intangible issues, such as users' affective preferences (i.e., scene and appeal).

To capture meaningful utterances from verbalisation occurring at the early stage of idea generation, we conducted a think-aloud protocol in which master craftsmen were instructed to imagine designing an artefact and freely express thoughts that accompany the idea embodiment verbally. The design task was to imagine designing any artefacts that associate with their previous experience i.e., fruit bowl, wooden craft bed, chair and table, they were free to simply express their ideas verbally or using a piece of paper.

The collected utterances were evaluated through a list of typical mindsets of craftsmen. The identified utterances were visualised and analysed by means of a concept network analysis to reproduce a structure of the individual's mental state. The framework consisted of the steps listed below (see Figure 1). 
Figure 1 Research framework

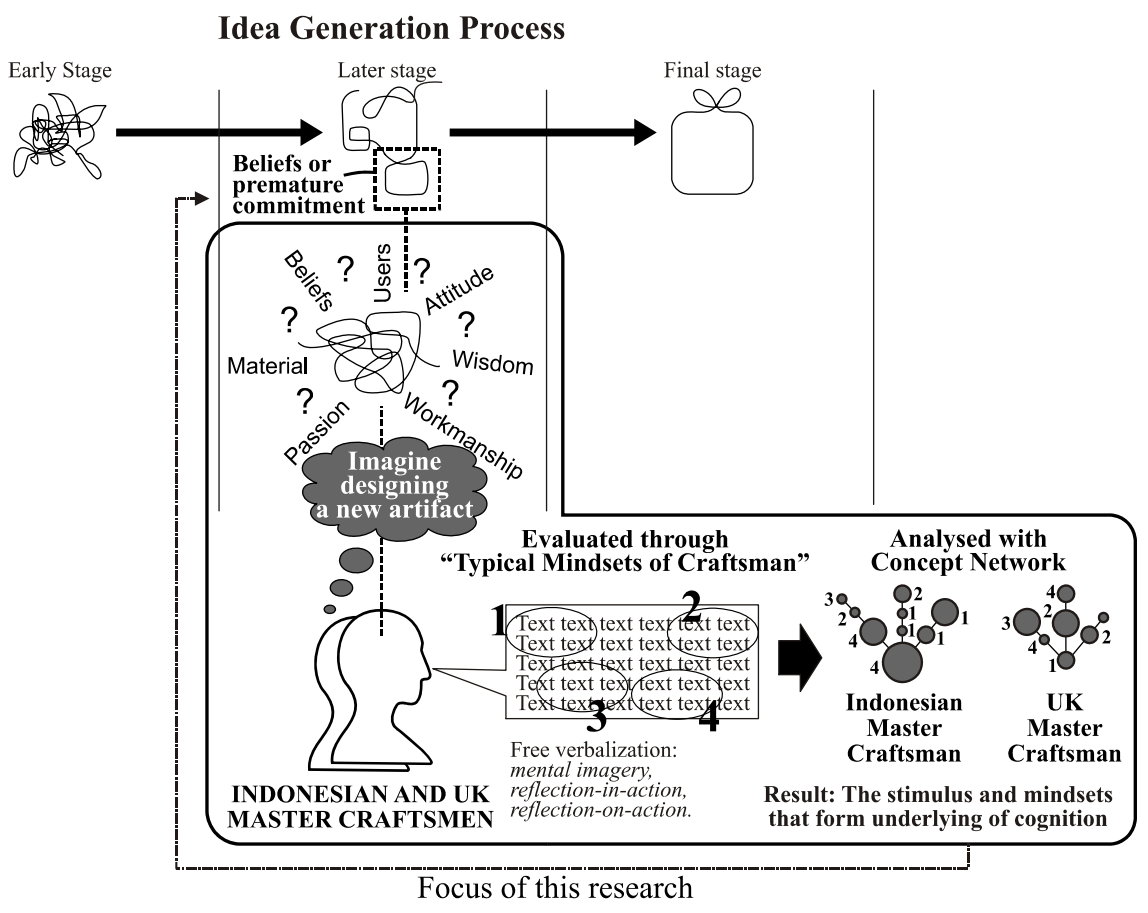

Methodological limitations of the study include:

a differences of country's living standards that probably affect their perspective in responding to the instruction

b different status and appreciation of master craftsperson in each country, where normally in the UK a master craftsperson is an entrepreneur, whilst in Indonesia, a master craftsperson is contracted/paid labour.

\subsection{Participants}

Eight subjects were selected to participate in this experiment: four Indonesian master craftsmen and four UK master craftsmen. All of them are known as master craftspeople who possess special skills in artistry and this ranged from woodcarving, woodturning, rattan work to bamboo weaving. Their special expertise has been passed down from one generation to another. The eight subjects (master craftsmen) had more than 25 years experience in craftsmanship. Either UK or Indonesian master craftsmen hold formal education which varies from high school to university level. They all practise their work in the suburban area. The economic and social background is quite different, where the UK master craftsmen lead their own workshop and live in the area of Buckinghamshire, whilst Indonesian master craftsman works as a contracted or paid worker who lives in a similar suburban area of Jepara, Indonesia. We assessed the participants' level of expertise, which were selected by establishing their recognition from peers concerned in the area of craftsmanship. 


\subsection{Procedure}

Subjects conducted a think-aloud protocol to search for new design ideas by imagining the design of a new artefact where they freely expressed their ideas verbally. We placed no constraints on time when they verbally expressed their ideas and engaged in spontaneous thinking. We avoided rigid instruction about types of the new artefact, market, or design functions to avoid excessive information which might be unfair and misleading. The minimal instructions ensured a neutral and unbiased process. The think-aloud protocol experiment was carried out separately with each participant to avoid mimicking or copying of ideas. The direct instruction was given as: 'please imagine designing a new artefact and freely express the ideas verbally' (see Figure 1).

\subsubsection{First stage rule of video transcription}

In this study, verbalisation is defined as conveying ideas through verbal communication (i.e., utterances) during engagement in a thinking process at the early stage of idea generation. The conceptual process was videotaped and the verbalisation was transcribed and sorted by its context. Utterances were transcribed according to the content substance. Verbalisation of Indonesian language was transcribed into English.

The following types of utterances were taken into account:

- utterances concerning conceptualisation (including expressions of vague of mental imagery)

- utterances concerning reflection-in-action or reflection-on-action (Schön, 1983).

The following types of utterances were excluded:

- instructions and utterances given by the researchers or other parties

- $\quad$ out of context utterances (i.e., non-related comments)

- $\quad$ post-design utterances (i.e., general technical process, previously-made artefact)

- repetitive contents

- broad knowledge of historical view.

\subsubsection{Second stage rule of keyword extraction}

- utterances were extracted when regarded as non-essential information

- $\quad$ alternative similar word is applied for clarity and readability

- $\quad$ similar repeated utterances are removed

- $\quad$ interjections or exclamations are omitted (i.e., hum, oh, wow, well, yeah, etc.)

- $\quad$ unnecessary phrases, prepositions and conjunctions are omitted (i.e., 'you know', 'well', 'all right,' etc.).

Further, we apply a matrix equation to create network graphs in two modes as follow:

a The matrix comprised of a $\mathrm{X}$ and $\mathrm{Y}$ axis, where the $\mathrm{X}$ axis represents the 'conceptual stimulus' and the $\mathrm{Y}$ axis represents typical mindsets during capturing the in-degree 
centrality (IDC). The IDC refers to the number of ties directed to a vertex (typical mindsets from conceptual stimulus). IDC is interpreted as a form of typical mindsets affected by conceptual stimulus.

$\mathrm{b}$ The matrix comprised of a $\mathrm{X}$ and $\mathrm{Y}$ axis, where the $\mathrm{X}$ axis represents the typical mindsets and the $\mathrm{Y}$ axis represents 'conceptual stimulus' during capturing the out-degree centrality (ODC). The ODC is the number of ties that the vertex directs to others (conceptual stimulus towards typical mindsets). ODC is the degree to which a conceptual stimulus forms beliefs or typical mindsets.

Finally, the matrix equation of ODC and IDC network graphs will display weak and strong connections between the two variables, which will be identified and interpreted to prove our hypothesis that either a barrier or potential seeds exist in cognitive dissonance, during conceptualisation at the early stage of idea generation.

\section{The experiment of conceptual ideation process}

\subsection{Background on typical mindsets of craftsman}

Glăveanu (2011) explains that a socio-cultural practice is one important characteristic being intrinsic to creativity which normally takes place and is studied as an ongoing and long-term activity. From a socio-cultural perspective creativity is considered social in nature and located in the space 'in between' the self and others. This means that this standpoint does not deny the role of the individual mindset within the socio-cultural nature of expertise.

Table 1 Identified list of typical mindsets of craftsman

\begin{tabular}{|c|c|c|c|}
\hline No & Typical mindsets & $\begin{array}{c}\text { Typical characteristic-related } \\
\text { issues }\end{array}$ & Literature \\
\hline 1 & Mastery & $\begin{array}{l}\text { Workmanship; craftsmanship; } \\
\text { tools }\end{array}$ & $\begin{array}{l}\text { Pye (1968), Yanagi (1989), Sennet } \\
\text { (2008) and Adamson (2007) }\end{array}$ \\
\hline 2 & Object-attribute & Dimension; material; shape & $\begin{array}{c}\text { Pye (1968), Yanagi (1989) and } \\
\text { Sennet (2008) }\end{array}$ \\
\hline 3 & Rationale & Market; users, buyers; pricing & Yanagi (1989) and Sennet (2008) \\
\hline 4 & Nostalgic & Nostalgic; historic & $\begin{array}{l}\text { Pye (1968), Yanagi (1989), Sennet } \\
\text { (2008) and Adamson (2007) }\end{array}$ \\
\hline 5 & Passionate & $\begin{array}{l}\text { Pride; satisfaction, } \\
\text { self-achievement; }\end{array}$ & $\begin{array}{l}\text { Pye (1968), Yanagi (1989), Sennet } \\
\text { (2008) and Adamson (2007) }\end{array}$ \\
\hline 6 & Wisdom & $\begin{array}{l}\text { Beliefs; commitment; } \\
\text { philosophy }\end{array}$ & $\begin{array}{l}\text { Pye (1968), Yanagi (1989), Sennet } \\
\text { (2008) and Adamson (2007) }\end{array}$ \\
\hline 7 & Modest & Naive; sincerity & Yanagi (1989) and Sennet (2008) \\
\hline 8 & Uncompromising & Unwavering; firm; rigid; ego & $\begin{array}{c}\text { Yanagi (1989), Sennet (2008) and } \\
\text { Adamson (2007) }\end{array}$ \\
\hline 9 & Sentimental & Romantic; solidarity; yearning & $\begin{array}{c}\text { Yanagi (1989), Sennet (2008) and } \\
\text { Adamson (2007) }\end{array}$ \\
\hline
\end{tabular}

We conducted an analysis of known studies of craftsman to identify the typical mindsets that are characteristic of a craftsman. The identified list of typical mindsets of craftsman 
was used as an independent variable, hereafter referred to as 'typical mindset.' Furthermore, the verbalised thoughts were extracted into keywords and hereafter referred to as 'conceptual stimulus'. This procedure was set up due to limited literature being found concerning personality traits of a craftsman.

Four main texts were employed, two classic literatures and two modern literature. Pye (1968) intensely observed craftsman's highly-workmanship performance. Yanagi (1989) deeply discusses the definition of craftspeople, the artefacts and its philosophy with special attention given to the indigenous folk-craft. The third text provides a more modern viewpoint, where Sennett (2008) discusses more actualisation of craftsman in the contemporary era from a sociological standpoint. Last, Adamson (2007), highlights and explores the importance of the concept of authenticity of the very practice of craft skill, which he proposes as cultural associations of craft - the 'pastoral' and 'amateur'. Even though each author has a different background and standpoint, there are common threads that can be drawn upon. We reviewed this qualitatively. If a characteristic-related issue was discussed intensively by at least two authors, this issue was determined as a typical mindset (see Table 1). Finally, nine typical mindsets of craftsman were identified as follows.

\section{Verbalised thoughts}

\subsection{Indonesian master craftsmen}

Historical and cultural background may contribute to ways of reacting and thinking. In the case of the Indonesian master craftsmen, most of their utterances were explicit issues, i.e., users' preference, buyers, skills and object properties (i.e., shape, dimension, type). Other utterances which were voiced less were related to implicit issues, i.e., partnership, sharing and expectations for common mutual benefit. The verbalised thoughts collected from utterances reflect their shallow expression of unassuming and resignation. Here are some excerpts related to pragmatism and technicality from their verbalised thoughts:

- "European buyers tend to request a single item, not multiple items, this is convenient for the craftsmen"

- "in order to offer a reasonable price, woodcarving work should be little and simple"

- "as long as it covers the production cost, I'll buy it, all workers have a job"

- "knock-down consideration for easy delivery"

- "strength and structure is not an issue if using leaves"

- "melamine finish is still required as a protection afterward"

- "the legs height can be $35 \mathrm{~cm}$ or $30 \mathrm{~cm}$ "

- "I am thinking of raw material supplies"

- "two types of weaving, the bottom part is wide and upper part is small"

- etc. 


\subsection{UK master craftsmen}

Besides containing explicit issues, i.e., function and object properties (i.e., shape, dimension, type), verbalised thoughts of UK master craftsmen also exhibit greater attention to implicit issues. Despite their concern regarding the object properties and functional issues, the UK master craftsmen profoundly expresses more philosophical issues, i.e., attitude, commitment and an eloquent knowledge of wisdom and passion. The event seemed to be a story-telling-like verbalisation, particularly in sharing their attitude and philosophy. The following is part of the collected abstract utterances related to wisdom and passion issues:

- "every detail right down to the grain and the knotting is so personal to our customer"

- "I was thinking, what they like, what they can not buy"

- "we don't make products, we make things which people love to own"

- "the love is a whole process and I keep them involved"

- "it's not just a work, it's a way to work, it's a thought behind it"

- "if they are negative about the work, it makes me ultra positive"

- "sometimes the wood will try to dictate only because there is unforeseen, we call it a flow"

- "sequence of materials, you have to start it from the bottom, deep in the Earth"

- "if I got a shape of a piece of stone, I wouldn't have another shape of a piece of stone touching it"

- etc.

\subsection{Keywords extraction: conceptual stimulus}

The issues raised by the two groups of craftsmen at first seemed quite similar, such as object properties and functional, yet each has a different emphasis. UK master craftsmen expressed object properties and functional by placing emphasis on a philosophical standpoint, while Indonesians place emphasis on a technical standpoint. UK master craftsmen expressed less about market, pricing, whereas it was very intensely discussed by Indonesian master craftsmen. To find out more details of the process of conceptualisation during the early stage of idea generation, we performed the evaluation and extraction of the verbalised thoughts. A keyword derived from utterances was extracted by applying constructed rules. The keywords hereafter referred to as 'conceptual stimulus' that represent a collection of structure of thoughts directed us to typical mindsets (see Tables $2 \mathrm{a}$ and $2 \mathrm{~b}$ ). The evaluation of the keyword was matched to the given code of identified typical mindsets of the craftsman. The codes are as follows:

1 mastery

2 object-attribute

3 rationale and so on (see Table 1). 
Table 2a Extracted verbalised thoughts or keywords referred to as 'conceptual stimulus' of Indonesian master craftsmen

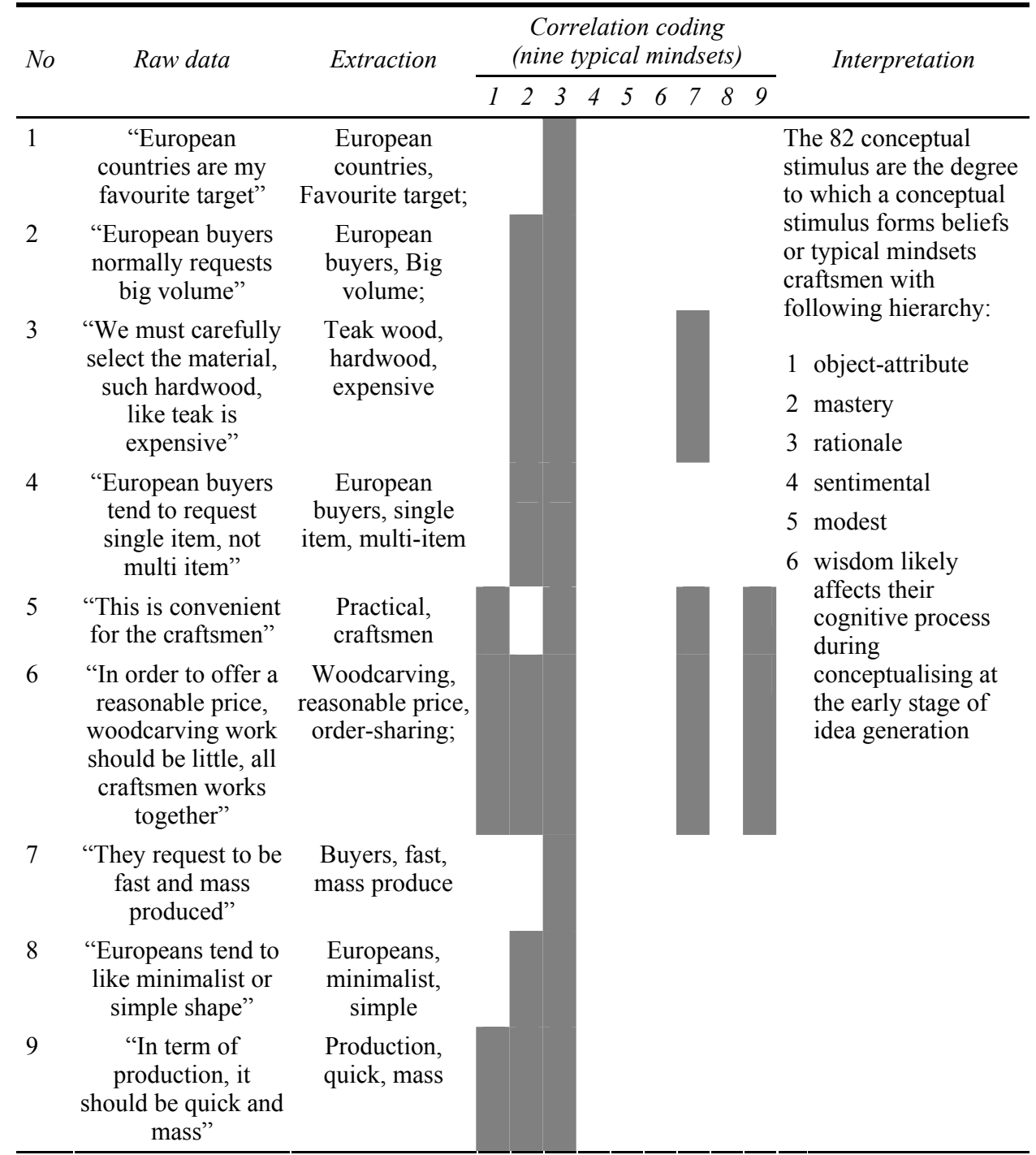

Notes: Partly shown due to page limitation,

Identified list of typical mindsets of craftsman (coding),

1: mastery,

2: object-attribute,

3: rationale,

4: nostalgic,

5: passionate,

6: wisdom,

7: modest,

8: uncompromising,

9: sentimental 
Table 2a Extracted verbalised thoughts or keywords referred to as 'conceptual stimulus' of Indonesian master craftsmen (continued)

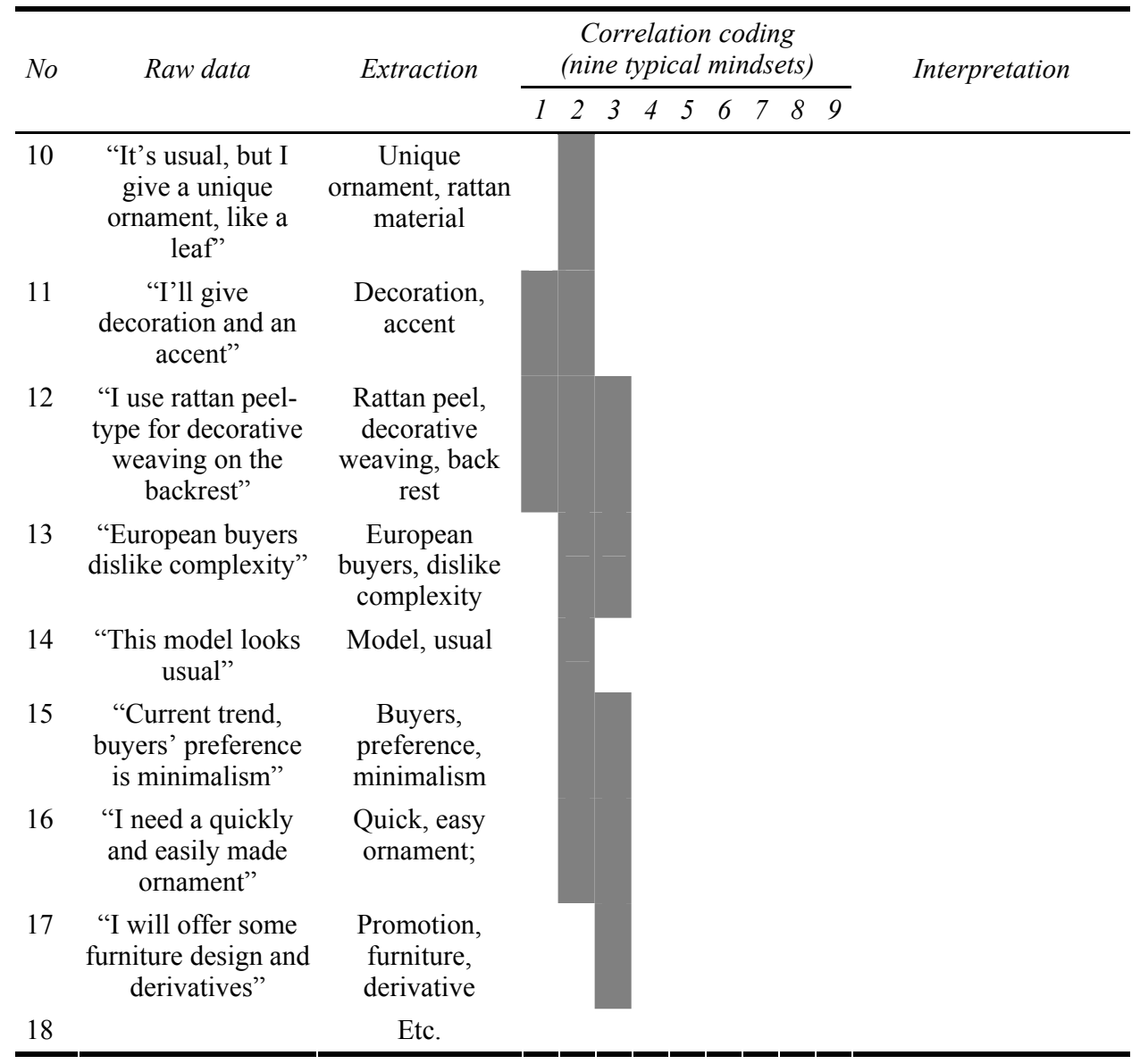

Notes: Partly shown due to page limitation,

Identified list of typical mindsets of craftsman (coding),

1: mastery,

2: object-attribute,

3: rationale,

4: nostalgic,

5: passionate,

6: wisdom

7: modest,

8: uncompromising,

9: sentimental 
Table 2b Extracted verbalised thoughts or keywords referred to as 'conceptual stimulus' of UK master craftsmen

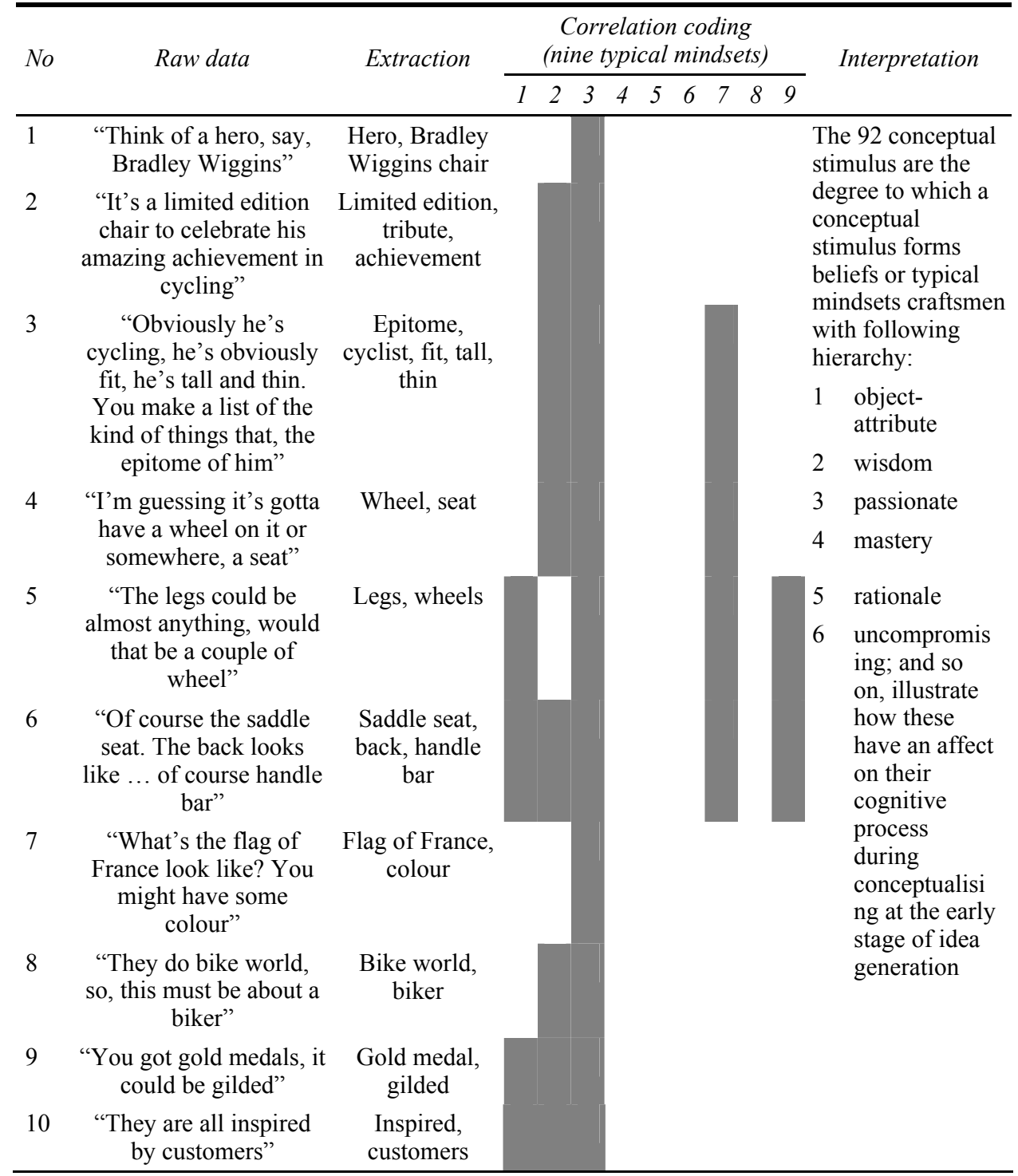

Notes: Partly shown due to page limitation,

Identified list of typical mindsets of craftsman (coding),

1: mastery,

2: object-attribute,

3: rationale,

4: nostalgic,

5: passionate,

6: wisdom,

7: modest,

8: uncompromising,

9: sentimental 
Table 2b Extracted verbalised thoughts or keywords referred to as 'conceptual stimulus' of UK master craftsmen (continued)

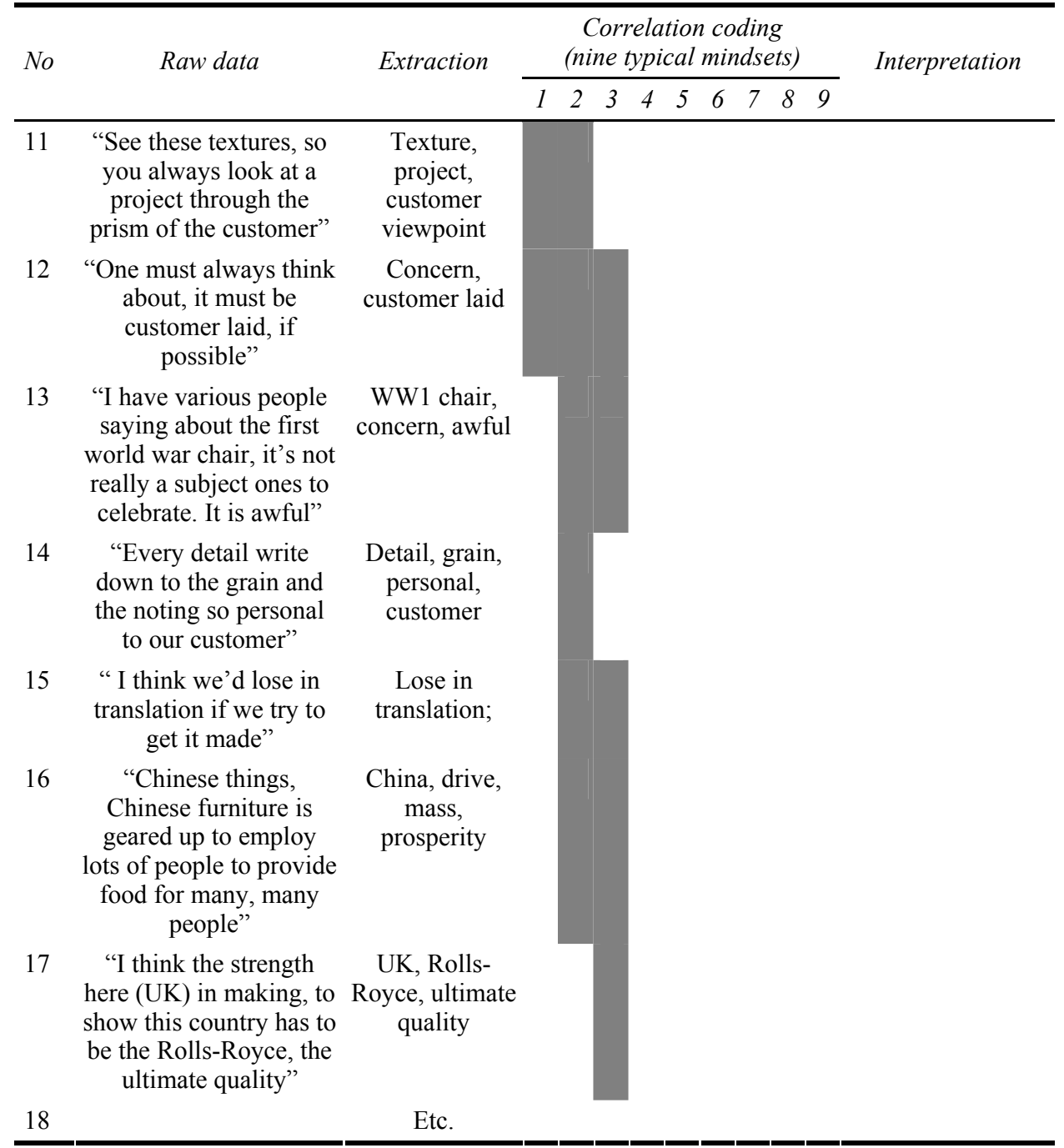

Notes: Partly shown due to page limitation,

Identified list of typical mindsets of craftsman (coding),

1: mastery,

2: object-attribute,

3: rationale,

4: nostalgic,

5: passionate

6: wisdom,

7: modest,

8: uncompromising,

9: sentimental

Furthermore, the correlation between conceptual stimulus and identified typical mindsets of craftsman was evaluated by looking at their commonalities. For example, utterance: $I$ intend to upgrade craftsmen's income, there's the simple idea of using leaves come from, 
which is quite practical. Extraction of the essential information into keywords (conceptual stimulus): support; income; leaves; practical. It was evaluated to have commonality with (2) object-attribute, (3) rationale, (7) modest, (9) sentimental. These keywords (conceptual stimulus) would have four directed links to the typical mindsets. This multi link will connect to other links to create a network graph which depicted the pattern of the structure of thoughts.

A network analysis was employed to create a network graph. The number of connections between the conceptual stimulus with typical mindsets of the craftsman in a form of vertices and arcs was displayed as a structure of thoughts. The degree of connections was calculated by a matrix equation that depicts the centrality score of the conceptual stimulus and the typical mindsets. For example, all of the conceptual stimulus directed connections were defined as a domain of ODC; while the nine typical mindsets pointed by arcs from the conceptual stimulus are calculated as IDC. The ODC (conceptual stimulus) provides information as the donors, where IDC (typical mindsets) represents the recipient. Next, the network can be analysed as it reproduces the conceptual network model of the individual's mental state. The data was visualised by the use of Pajek 2.05 software based on the 2D layers in the Y direction for Figures 2, 3(a) and 3(b); and algorithm of Fruchterman and Reingold for Figures 4(a) and 4(b) (de Nooy et al., 2005).

Tables $2 \mathrm{a}$ and $2 \mathrm{~b}$ (Indonesia and $\mathrm{UK}$ ) are simply showing the raw data and coding. However, the IDC and ODC performed by matrix equation are later used to calculate the strong and weak connections between conceptual stimulus and the typical mindsets. Therefore, at this stage it is still difficult to interpret latent cognitive resources from the data shown in Table $2 \mathrm{a}$ and $2 \mathrm{~b}$.

Table 3 Correlation between conceptual stimulus and typical mindsets (partly shown)

\begin{tabular}{|c|c|c|}
\hline No & Conceptual stimulus (82) (Indonesian) & $\begin{array}{c}\text { Correlation to the typical mindsets } \\
\text { (total) }\end{array}$ \\
\hline 1 & European countries, favourite target & \multirow{7}{*}{$\begin{array}{l}\text { Mastery (34), object-attribute (53), } \\
\text { rationale (37), nostalgic }(0), \\
\text { passionate }(0), \text { wisdom (8), modest } \\
(10), \text { uncompromising }(0), \\
\text { sentimental }(17)\end{array}$} \\
\hline 2 & European buyers, big volume & \\
\hline 3 & Manpower, availability & \\
\hline 4 & Craftsmen, sharing, solidarity & \\
\hline 5 & Support, income, leaves, practicality & \\
\hline \multirow[t]{2}{*}{6} & Bamboo treatment, shaping & \\
\hline & Etc. & \\
\hline No & Conceptual stimulus (92) (UK) & $\begin{array}{c}\text { Correlation to the typical mindsets } \\
\text { (total) }\end{array}$ \\
\hline 1 & Limited edition, tribute, achievement & \multirow{7}{*}{$\begin{array}{l}\text { Mastery (21), object-attribute (61), } \\
\text { rationale (16), nostalgic (14), } \\
\text { passionate (35), wisdom (38), modest } \\
\text { (8), uncompromising (16), } \\
\text { sentimental (8) }\end{array}$} \\
\hline 2 & WW1 chair, concern, awful & \\
\hline 3 & Material, sustain, throw-away society & \\
\hline 4 & Life process, volcano, igneous, intrusion, magma & \\
\hline 5 & Sequence, materials, bottom, deep, earth & \\
\hline \multirow[t]{2}{*}{6} & Love, process, involved & \\
\hline & Etc. & \\
\hline
\end{tabular}


The number of utterances and the number of words which are extracted into the conceptual stimulus were not taken into account as we did not compare it quantitatively, but we did pay attention to patterns and thought structures. After applying the rule of transcription and extraction, we obtained 82 conceptual stimulus from the Indonesian master craftsmen and 92 conceptual stimulus from the UK master craftsmen. Each conceptual stimulus was evaluated qualitatively in correlation with the nine typical mindsets with the following results:

From the total score of the correlation shown in Table 3, we observed a slight tendency of the typical mindsets from each group of the craftsmen. This showed only the basic data. Next, we wanted to understand how the conceptual stimulus intertwined with each other to form a particular pattern of cultural uniqueness. Here, a conceptual stimulus is like a single concept that has multiple connections to and from the stems from other concepts.

Frequently the utterances were found to jump from one issue to another issue and sometimes repeat the same story of particular events. Through the visualisation of the graph network, the thoughts were structured as collected conceptual stimulus directed to typical mindsets and vice versa. Here, the shifts in the utterances were no longer an issue. The network structure with its matrix equation is based on a degree of centrality. A conceptual stimulus is a vertex that measures its relative importance within a graph. Multi-connection represents density which shows how influential a conceptual stimuli/concept is within a conceptual network. The degree of centrality is defined as the number of ties which occur at a vertex. This degree can be interpreted in terms of a concept/conceptual stimulus flowing through the network. We employed two separate measures of the degree of centrality. Accordingly, IDC refers to the number of ties directed to a vertex (typical mindsets from conceptual stimulus); IDC is interpreted as a form of typical mindsets affected by conceptual stimulus. ODC is the number of ties that the vertex directs to others (conceptual stimulus towards typical mindsets). ODC is the degree to which a conceptual stimulus forms beliefs or typical mindsets (see equation of ODC and IDC; Tables 4a and 4b).

Table 4a An example of matrix of conceptual stimulus and typical mindsets applying equation of ODC

\begin{tabular}{|c|c|c|c|c|c|c|c|c|c|c|c|}
\hline & & & \multicolumn{9}{|c|}{ Typical mindsets } \\
\hline & & & 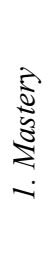 & 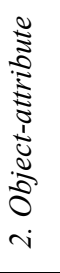 & 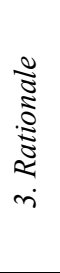 & 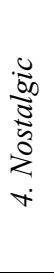 & 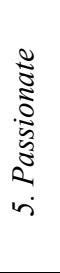 & $\begin{array}{l}5 \\
\vdots \\
\vdots \\
\vdots \\
0 \\
0\end{array}$ & 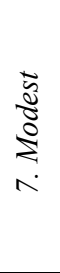 & 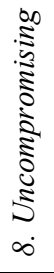 & 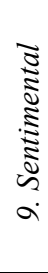 \\
\hline \multirow{5}{*}{ 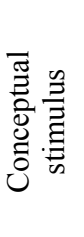 } & 1 & European countries, favourite target & 0 & 0 & 1 & 0 & 0 & 0 & 0 & 0 & 0 \\
\hline & 2 & Strength, structure & 1 & 1 & 1 & 0 & 0 & 0 & 0 & 0 & 0 \\
\hline & 3 & Manpower, availability & 0 & 0 & 1 & 0 & 0 & 0 & 0 & 0 & 1 \\
\hline & & Craftsmen, sharing, solidarity & 0 & 0 & 1 & 0 & 0 & 1 & 0 & 0 & 1 \\
\hline & Et & & & & & & & & & & \\
\hline
\end{tabular}


Table 4b An example of matrix of conceptual stimulus and typical mindsets applying equation of IDC

\begin{tabular}{|c|c|c|c|c|c|c|c|}
\hline & & & \multicolumn{5}{|c|}{ Conceptual stimulus } \\
\hline & & & 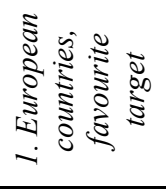 & 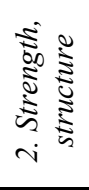 & 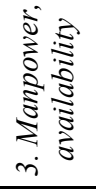 & 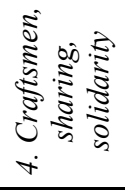 & 离 \\
\hline \multirow{9}{*}{ 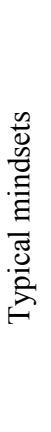 } & 1 & Mastery & 0 & 1 & 0 & 0 & \\
\hline & 2 & Object-attribute & 0 & 1 & 0 & 0 & \\
\hline & 3 & Rationale & 1 & 1 & 1 & 1 & \\
\hline & 4 & Nostalgic & 0 & 0 & 0 & 0 & \\
\hline & 5 & Passionate & 0 & 0 & 0 & 0 & \\
\hline & 6 & Wisdom & 0 & 0 & 0 & 1 & \\
\hline & 7 & Modest & 0 & 0 & 0 & 0 & \\
\hline & 8 & Uncompromising & 0 & 0 & 0 & 0 & \\
\hline & 9 & Sentimental & 0 & 0 & 1 & 1 & \\
\hline
\end{tabular}

Equation of ODC with two-mode networks:

$$
A=\left(a_{i j}\right)\left[\begin{array}{lllll}
a_{11} & \cdots & a_{1 j} & \cdots & a_{1 n} \\
\vdots & & \vdots & & \vdots \\
a_{i 1} & & a_{i j} & \cdots & a_{i n} \\
\vdots & & \vdots & & \vdots \\
a_{n 1} & & a_{n j} & \cdots & a_{n n}
\end{array}\right] \quad a_{i j}=\left[\begin{array}{lll}
\text { word rate } & i \rightarrow j & \text { Out } \\
0 & i \rightarrow j & \text { None }
\end{array}\right]
$$

Out-Degree centrality: $D_{i}=\frac{\sum_{i=1}^{n} a_{i j}}{n}$ (Note: $n$ is the number of nodes)

Equation of IDC with two-mode networks:

$$
A=\left(a_{i j}\right)\left[\begin{array}{lllll}
a_{11} & \cdots & a_{1 j} & \cdots & a_{1 n} \\
\vdots & & \vdots & & \vdots \\
a_{i 1} & & a_{i j} & \cdots & a_{i n} \\
\vdots & & \vdots & & \vdots \\
a_{n 1} & & a_{n j} & \cdots & a_{n n}
\end{array}\right] \quad a_{i j}=\left[\begin{array}{lll}
\text { word rate } & i \rightarrow j & \text { Out } \\
0 & i \rightarrow j & \text { None }
\end{array}\right]
$$

Out-Degree centrality: $D_{i}=\frac{\sum_{i=1}^{n} a_{i j}}{n}$ (Note: $n$ is the number of nodes) 


\section{Concept networks of the typical mindsets}

\subsection{Indonesian master craftsmen}

The IDC forms three domains of typical mindsets based on their strong correlation between typical mindsets and the conceptual stimulus. The strongest domain is (1) object-attribute with an IDC score of 0.59 point. The second strong domain of typical mindsets is $(2 \mathrm{a})$ rationale with 0.41 point and $(2 \mathrm{~b})$ mastery 0.38 point. The third domain of typical mindsets is (3a) sentimental 0.19 point, (3b) modest 0.11 point and (3c) wisdom 0.09 point which is considered weak. The typical mindsets of nostalgic, passionate and uncompromising were found to be 0.00 point which means that no correlation was found. These three typical mindsets of Indonesian craftsmen;

1 object-attribute

2a mastery

$2 b$ rationale

3a sentimental

3b modest

3c wisdom likely affects their cognitive process during conceptualising at the early stage of idea generation [see Figure 2(a)].

Figure 2 Domain of typical mindsets that generate conceptual stimulus, (a) Indonesian (b) UK (see online version for colours)

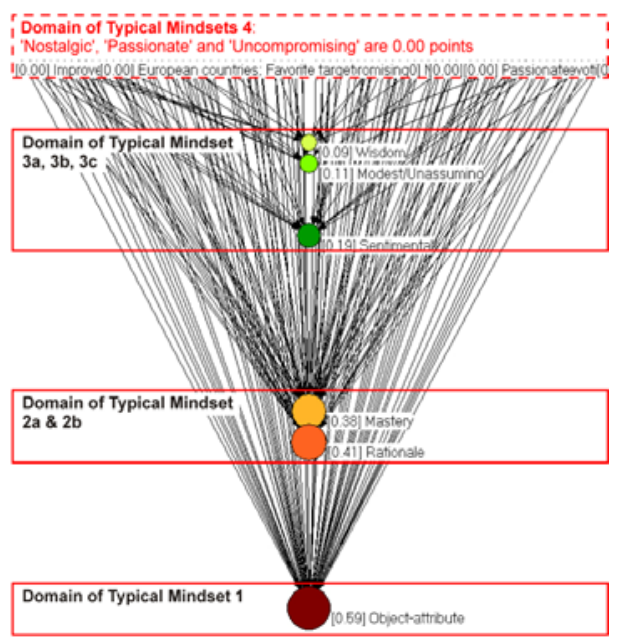

(a)

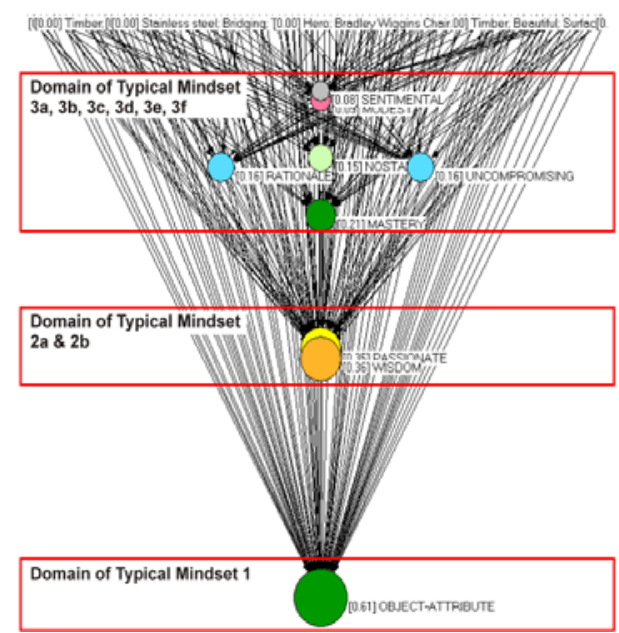

(b) 


\subsection{UK master craftsmen}

Three domains were identified based on strong correlation between typical mindsets and the conceptual stimulus, but these are different types of typical mindsets compared to those found in Indonesian master craftsmen. The strongest domain is (1) object-attribute with an IDC score of 0.61 point. The second strongest domain of typical mindsets is (2a) wisdom with 0.36 point and (2b) passionate with 0.35 point. The third domain of typical mindsets is mastery 0.21 point, rationale 0.16 point, uncompromising 0.16 point, nostalgia 0.15 point, modest 0.09 point and sentimental 0.08 point which is considered weak. All nine typical mindsets were found from UK master craftsmen's verbalisation. These are three typical mindsets of UK craftsmen;

1 object-attribute

2a wisdom

$2 \mathrm{~b}$ passionate

3a mastery

$3 b$ rationale

$3 \mathrm{c}$ uncompromising

$3 \mathrm{~d}$ nostalgic

3e modest

3f sentimental illustrate how these have an affect on their cognitive process during conceptualising at the early stage of idea generation [see Figure 2(b)].

\section{Networks of the conceptual stimulus}

\subsection{Indonesian master craftsmen}

The extracted 82 keywords or conceptual stimulus of Indonesian master craftsmen were visualised to capture its connections (ties) with typical mindsets. The conceptual stimulus is the degree to which a conceptual stimulus forms beliefs or typical mindsets. A conceptual stimulus may contribute to more than one typical mindsets, the greater the number of ties (multi connection) from one conceptual stimuli (a vertex) signifies an influential donor. However, only vertices with multiple ties that are accompanied by a significant number of donors are defined as solid donors, i.e., clusters of conceptual stimulus 3 and 4 have a significant number of vertices. Clusters of conceptual stimulus 1 and 2 are considered not solid and clusters of conceptual stimulus 5 represent only a single tie which is deemed as a weak donor. Therefore, conceptual stimuli 1, 2 and 5 are not taken into account (see Figure 3a). 
Figure 3a Conceptual stimuli form a typical mindset (Indonesian master craftsmen) (see online version for colours)

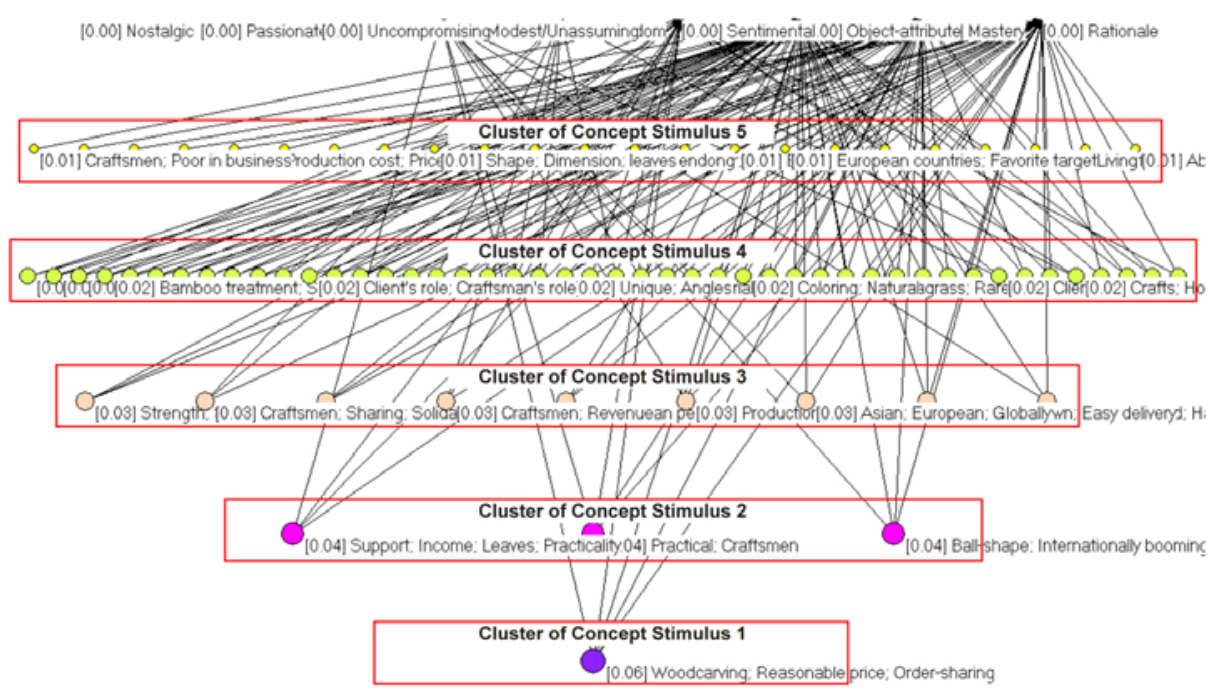

\subsection{UK master craftsmen}

The extracted 92 keywords or conceptual stimulus of UK master craftsmen were visualised to capture its ties with typical mindsets. The clusters conceptual stimuli 2, 3 and 4 have multi ties and a solid number of vertices, which are then defined as influential donors. The cluster of conceptual stimulus 5 represents a cluster of single tie vertices which is deemed as a weak donor and likewise, the cluster of conceptual stimulus 1 that comprises multi ties, however this only consists of a single vertex, thus both are not taken into account (see Figure 3b).

Figure 3b Conceptual stimuli form a typical mindset (UK master craftsmen) (see online version for colours)

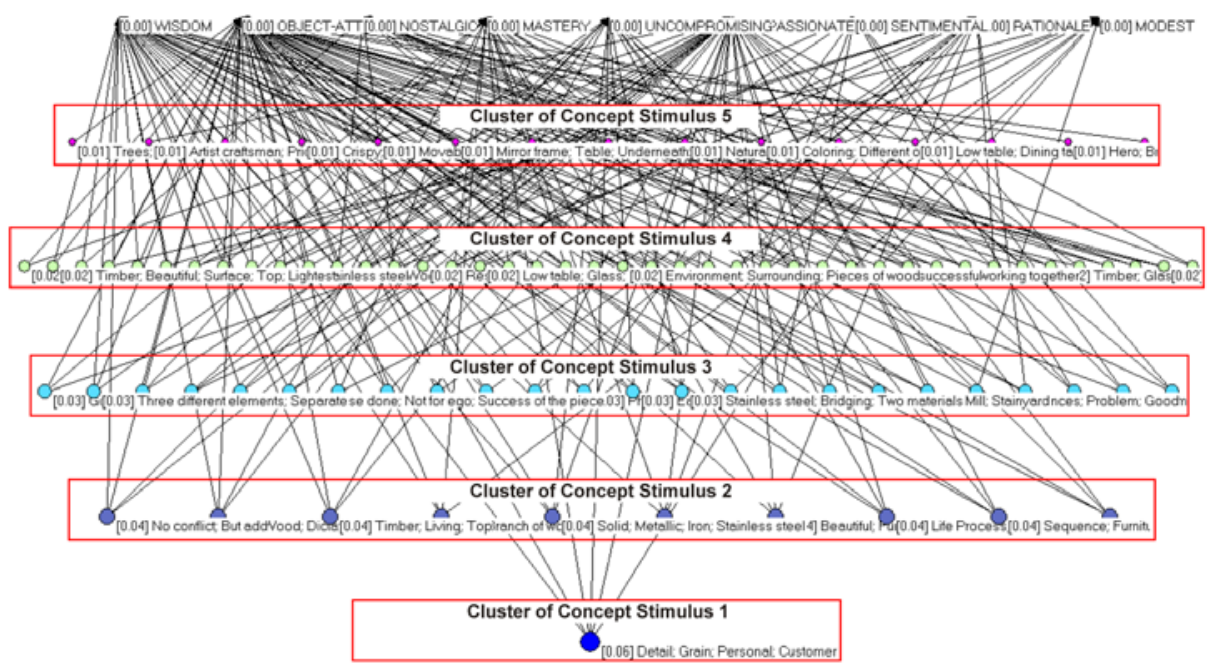




\section{Analysis of the concept networks}

\subsection{Indonesian master craftsmen}

The domain of typical mindset 1 of object-attribute ( 0.59 point) was the strongest domain [see Figure 2(a)], followed by a strong domain of typical mindset 2 (2a and 2b) rationale ( 0.41 point $)$ and mastery ( 0.38 point). The concept network depicts that conceptual stimulus such as service to buyers, big order; European buyers, dislike complexity; raw material, supplies; shape, size, users' preference; knock-down, easy delivery; support, income, leaves, practicality; production cost, expensive; Asian, European, globally; etc. greatly contribute to the two strongest domains of typical mindsets 1 and 2 : object-attribute; rationale and mastery [see Figure 2(a); and Figure 4a, the red dotted squares]. We interpreted that these strong typical mindsets: object-attribute, rationale and mastery represent an explicit consideration that greatly affects conceptual generation of Indonesian master craftsmen.

Furthermore, the domain of typical mindsets 3, comprised sentimental, modest and wisdom were found to be contrasting as this domain represents an implicit consideration and a weak typical stimulus [see Figure 2(a)]. This differs from the previous strong typical mindsets, which contains explicit consideration. These weak typical mindsets are sentimental $(0.19$ point $)$, modest $(0.11$ point $)$ and wisdom (0.09 point). They are generated by the conceptual stimulus, such as: craftsman, sharing, solidarity; collaboration, order sharing; coordinating, partnership; etc. This exhibits a culturally-unique illustration of the conceptual ideation process, where the strong explicit-related typical mindsets i.e., object-attribute, mastery and rationale conflict with the weak implicit-related typical mindset like sentimental, modest and wisdom. These three implicit-related typical mindsets most likely illustrate that Indonesian master craftsmen encounter cognitive dissonance of conceptualisation. This conflict can be observed by looking that their conceptualisation which is tied to one or more of the weak implicit-related typical mindset, but at the same time also tied or untied to one or more of the strong explicit-related typical mindset (see Figure 4a; the red dotted circles).

Figure 4a The conceptual stimulus and typical mindsets network structure of Indonesian master craftsmen (see online version for colours)

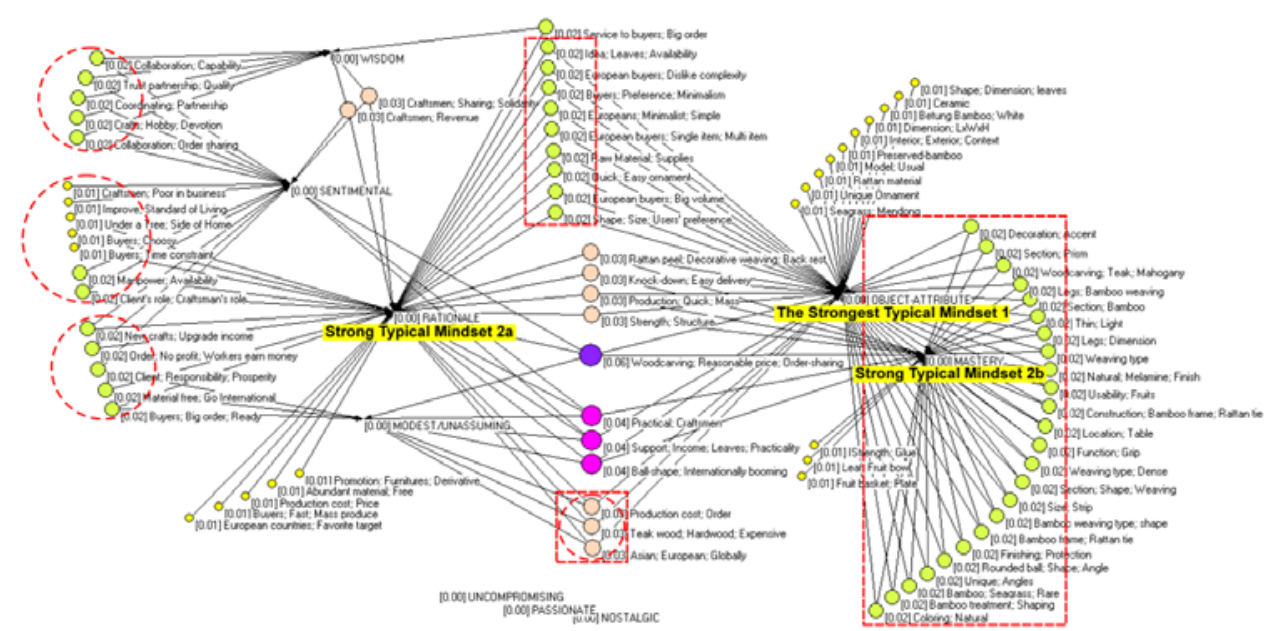


The red dotted square represents vertices and arcs (conceptual stimulus) that are tied directly to one or more of the three strong typical mindsets (object-attribute, rationale and mastery) and these are intertwined directly within those three strong typical mindsets. This means conceptual stimulus within the red dotted squares definitely contribute to form a strong typical mindset.

The red dotted circle represents vertices and arcs (conceptual stimulus) that are tied directly to one or more of the three weak typical mindsets (wisdom, modest and sentimental) and these are also tied or untied to one or more of the three strong typical mindsets (object-attribute, rationale and mastery). Those representing conceptual stimulus within the red dotted circle are interpreted as a weak expectancy that may cause difficulties or conflicts of cognition with the strong beliefs of conceptual stimulus. Those conflicts of conceptual stimulus are: collaboration, capability; trust, partnership, quality; collaboration, order sharing; manpower, availability; improve, standard living; order, no profit, workers earn money; client, responsibility, prosperity.

Furthermore, the overlapped red dotted square and red dotted circle represents an overlapping strong and weak tie (conceptual stimulus). This overlapping tie signifies mutual cognition and no occurrence of conflict or cognitive dissonance (see Figure 4a).

\subsection{UK master craftsmen}

The typical mindset 1 of object-attribute ( 0.61 point $)$ was the strongest domain of typical mindset [see Figure 2(b)], followed by a domain of typical mindsets 2 of wisdom ( 0.36 point $)$ and passionate $(0.35$ point $)$. The concept network depicts that conceptual stimulus such as no conflict, but add; wood; dictate, unforeseen, flow; UK, Rolls-Royce, ultimate quality; beautiful, functional; responding the wood, purpose; size; deviation of grain; environmental, honest; differences, possibility; aesthetically successful; Van Gogh, irises, different colour; etc. greatly contribute to the two strong domains of typical mindsets 1 and 2: object-attribute; wisdom and passionate [see Figure 2(b); and Figure $4 \mathrm{~b}$, the red dotted squares]. These significantly differ to the Indonesian master craftsmen, although object-attribute seems to be the strongest typical mindset, however most of the conceptual stimulus contributed to typical mindsets 1 and 2 are implicit-related (see Figure 3b, cluster of conceptual stimulus, 2, 3 and 4). We interpreted these strong typical mindsets: object-attribute; wisdom and passionate as an implicit consideration that greatly influences the conceptual ideation of UK master craftsmen.

Another set of typical mindsets also existed, however those are considered weak being positioned in the domain of typical mindsets 3 . It is comprised of mastery ( 0.21 point), rationale $(0.16$ point $)$, uncompromising ( 0.16 point $)$, nostalgic ( 0.15 point $)$, modest $(0.09$ point $)$ and sentimental $(0.08$ point $)$. These weak typical mindsets were found to be a mix of explicit-implicit-related considerations [see Figure 2(b)]. This differs from the previous strong typical mindsets, which contains more implicit consideration. These weak explicit-implicit-related typical mindsets are contributed to by the conceptual stimulus, such as: walnut, avoid much treatment; carve, brown rose, wild rose; epitome, cyclist, fit, tall, thin; client, request, practical; King Harold, choice, wood; etc. (see Figure $4 \mathrm{~b}$; the red dotted circles).

Ultimately, the conceptual ideation process of UK master craftsmen was greatly influenced by their strong sense of implicit-related typical mindsets i.e., object-attribute, wisdom and passionate, that compromise with contradictory explicit-implicit-related typical mindsets such as rationale. This mix of explicit-implicit-related typical stimuli 
suggests that UK master craftsmen also encounter cognitive dissonance of conceptualisation (see Figure 4b; the red dotted circles).

Figure 4b Conceptual stimulus and typical mindsets network structure of UK master craftsmen (see online version for colours)

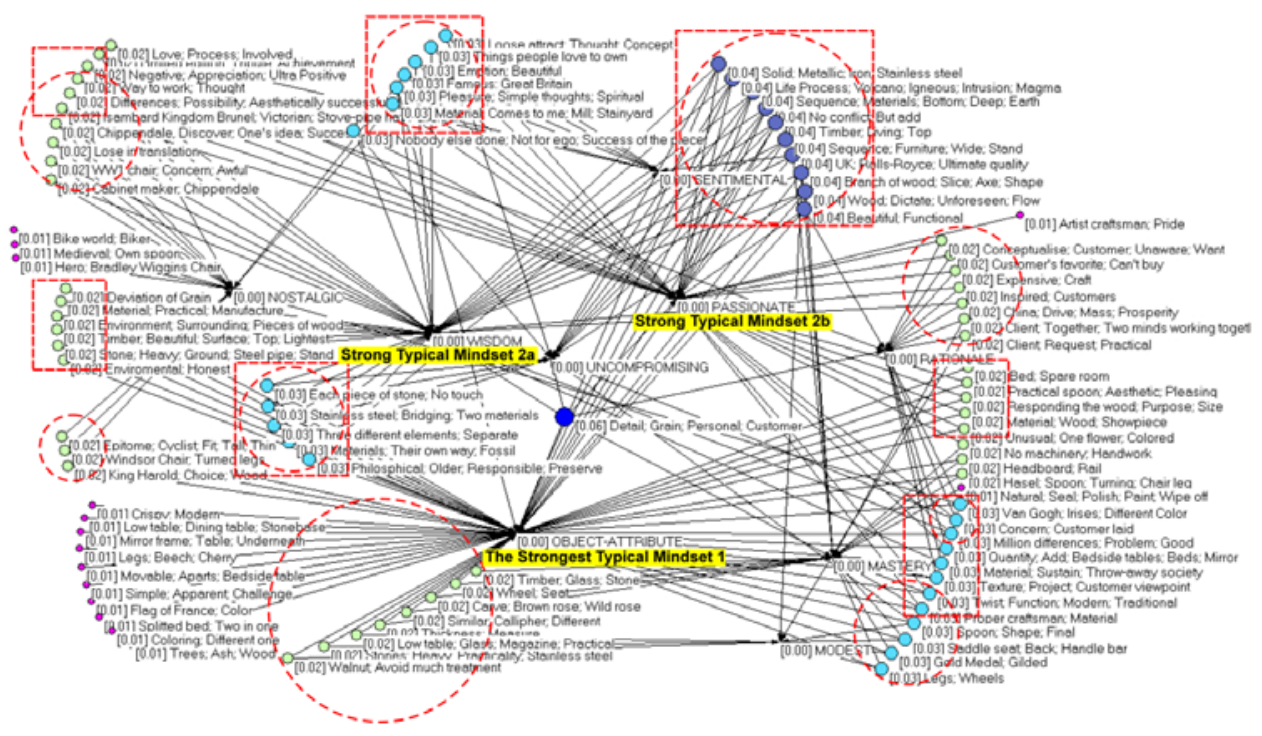

The conceptual stimuli tied to typical mindsets of object-attribute, wisdom and passionate were highly influential to form strong typical mindsets. Meanwhile, the conceptual stimulus within the red dotted circle represents a weak expectancy that may cause difficulties or conflicts of cognition with the strong beliefs of conceptual stimulus. Those conflicts can be observed from the conceptual stimuli that mostly express passion/wisdom issues with technical issues, i.e., similar, callipher, different; windsor chair, turned legs; WWIchair; concern; awful; cabinet maker, chippendale; client; request; practical; gold medal, gilded; saddle seat, back, handle bar; etc. (Figure 4b).

For the illustration of cognitive dissonance, see Figure $4 \mathrm{~b}$. The red dotted square given by vertices and arcs (conceptual stimulus) shows those that are tied directly to one or more of the three strong typical mindsets (object-attribute, wisdom and passionate) and intertwined directly within those three strong typical mindsets. This means conceptual stimuli within the red dotted squares definitely contribute to form strong typical mindsets.

The red dotted circles represented by vertices and arcs (conceptual stimulus) show those that are tied directly to one or more of the six weak typical mindsets (mastery, rational, uncompromising, nostalgic, modest and sentimental) and are also untied or tied to one or more of the three strong typical mindsets (object-attribute, wisdom and passionate). Those of the conceptual stimulus within the red dotted circle are interpreted as a weak expectancy that may cause difficulties or conflicts of cognition with the strong beliefs of conceptual stimulus.

The overlapped red dotted square and red dotted circle represents an overlapping of both strong and weak ties that signify mutual cognition having no occurrence of conflict or cognitive dissonance (see Figure $4 b$ ). 


\section{Discussion}

\subsection{Characteristic of the conceptual ideation process of master craftsmen}

A craftsman's cognitive capacity is greatly influenced by his/her attributes, such as culture, beliefs and insights. At some point, these attributes are regarded as an advantage or even a barrier. A perceptual barrier is created by old ways of thinking and responding (Martindale, 1995). In the craft tradition, a repeated-type experience has shaped a craftsman's ability to exploit with very subtle ways, but he/she has no theoretical understanding of how these effects are achieved (Steadman, 2008). The conceptual ideation process was generated from mindsets and stimulus that were intertwined. Therefore, every mindset and stimulus has a role either as potential or barrier.

In the case of Indonesian master craftsmen, their conceptual stimulus i.e., service to buyers, big order; European buyers, dislike complexity; raw material, supplies; shape, size, users' preference; knock-down, easy delivery; support, income, leaves, practicality; production cost, expensive; Asian, European, globally; etc. has constructed a typical mindset which stimulates a pragmatic viewpoint. This typical mindset may be seen as cognitive resources used in conceptualising that maintain explicit considerations. These explicit considerations lead their conscious mind to be stereotypical and follow the rule of familiarity to respond to issues of buyers, material, dimension, quantity, production cost and technique. This makes their conceptual thoughts conventional which avoids any radical changes. However, their weak typical mindsets (sentimental, modest and wisdom) that generates conceptual stimulus, such as: sharing, solidarity; collaboration, order sharing; coordinating, partnership; etc. demonstrate an urge of accessing more implicit realms such solidarity, sincerity, commitment. We believe at this point that a master craftsman encounters conflicting cognitions to maintain strong typical mindsets (beliefs) from various unrelated conceptual stimulus.

In short, Indonesian master craftsmen's conceptualisation is greatly influenced by typical mindsets of object-attribute that emphasise rationale and mastery that in turn stimulate a pragmatic viewpoint. However, at the same time this is contradictory with typical mindsets of sentimental that consider solidarity. The examples of their urge to access a more implicit realm such solidarity are as follows (underlined texts):

- "I intend to upgrade craftsmen's income, there's the simple idea of using leaves, which is quite practical"

- "we need to manage sharing with other craftsman as partner"

- "as long as it covers the production cost, I'll buy it, all workers have job"

- "we need to manage sharing with other craftsman as partner"

- "a client should be able to improve a living standard of a craftsmen"

- etc.

For the UK master craftsmen, their conceptual stimulus i.e., no conflict, but add; wood; dictate, unforeseen, flow; UK, Rolls-Royce, ultimate quality; beautiful, functional; responding the wood, purpose; size; deviation of grain; environmental, honest; differences, possibility; aesthetically successful; van Gogh, irises, different colour; etc. has contributed to a typical mindset of rigour. Although, the object-attribute 
is the strongest typical mindset much of the conceptual stimulus strongly exhibits implicit-related consideration. These implicit-related considerations bring a feeling of pride, commitment and satisfaction along with their conceptualisation. This becomes their familiarity enabling them to think in a conventional manner to maintain their rigour and passion of their established belief system (tradition). However, their weak typical mindsets (mastery, rationale, uncompromising, nostalgic, modest and sentimental) generated conceptual stimulus that most of them tied between explicit-implicit considerations. The examples are as follows (explicit considerations are underlined): epitome, cyclist, fit, tall, thin; king harold, choice, wood; windsor chair, turned legs; WWIchair; concern; awful; cabinet maker, chippendale; gold medal, gilded; saddle seat, back, handle bar; etc. Clearly, a master craftsman encounters conflicting cognitions to maintain strong implicit-related typical mindsets towards weak explicit-related conceptual stimulus.

In short, UK master craftsmen's conceptualisation greatly considered strong typical mindsets of object-attribute that emphasised wisdom and passionate that in turn indicate a rigorous mind, but at the same time giving contradictory attention to the weak typical mindsets of rationale that appears accommodating. The examples of their strong attention to pride and wisdom that still involves accommodating issues are as follows (underlined texts):

- "see these textures, so you always look at a project through the prism of the customer"

- "a lot of pleasure, out from very simple think, not just complicated, it's also social spiritual impact"

- "I'm responding the woods, that's fine what it is, that's a good table top size"

- "the love is a whole process, I keep them involved, if they negative about the work, it makes me ultra positive"

- "I was thinking what they like, what you can not buy"

- etc.

This study reveals that there are some domains of strong typical mindset that are inherent in ultimate mastery, whereas at the same time it limits other domains of typical mindset. The strong typical mindsets are things that a craftsman is familiar with which maintain their beliefs and conventional thought, which may be known as a barrier. These mindsets generate the conceptual stimulus. These stimuli are how they respond to and interpret the object, function, user and beliefs. The more conventional the ideas the more they are being secure within the strong typical mindsets. However, there is consistently minor attention given to other domains of typical mindset which is likely to be contradictory (i.e., Indonesians craftsman: pragmatic yet solidarity; UK craftsmen: rigour yet accommodating). This minor attention may be regarded as a weak stimulus that has potential to balance a fixed and strong typical mindset. A true creative process allow conflicts to occur and this conflict is positively exploited, i.e., 'making familiar strange' or 'bisociation' theory (Gordon, 1961; Koestler, 1964).

A presence of weak conceptual stimulus, which allegedly is contradictory towards strong typical mindsets, provides potential to lead an unconventional way of thinking. Curiosity towards unfamiliarity is one way of a creative individual conceptualising. 
Below is an illustration of the conceptualisation process of the Indonesian craftsman that is based on the pragmatic which slightly involves the contradictory, like solidarity (see Figure 5, left side), whereas UK craftsmen's conceptualisation places high attention upon rigour but shows a minor contradiction with accommodating (see Figure 5, right side).

Figure 5 Illustration of a craftsman's cognitive dissonance in conceptual process

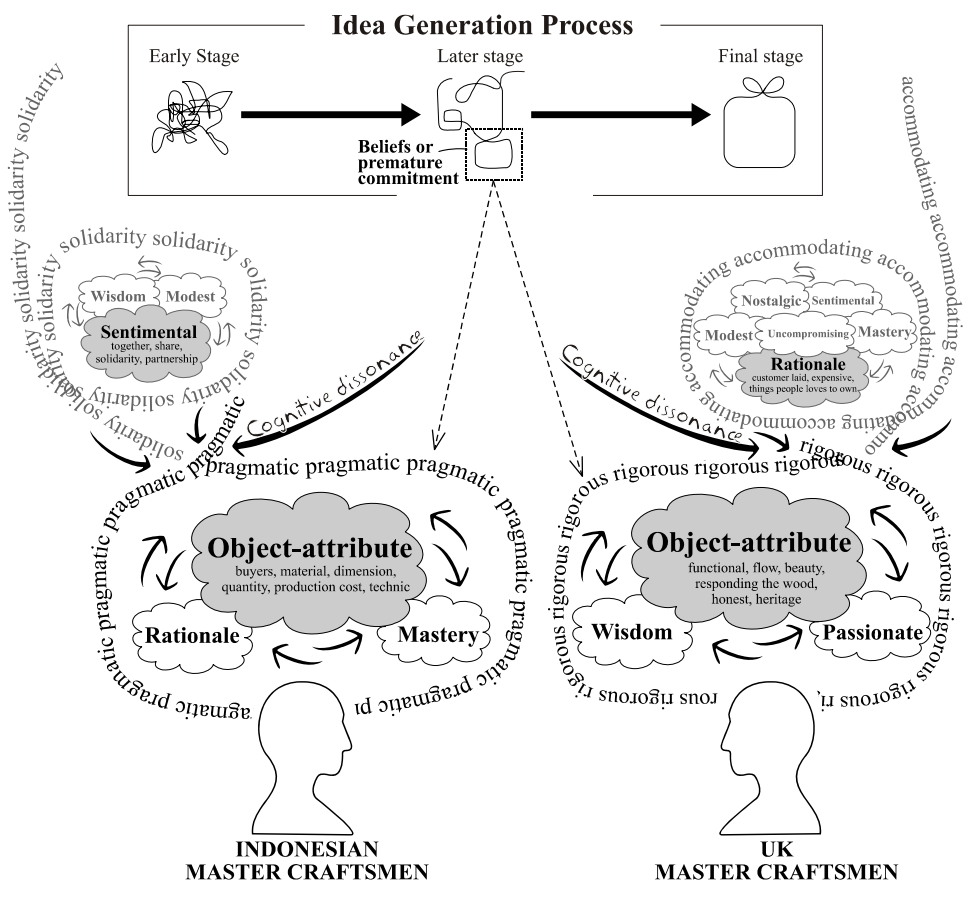

\section{Conclusions}

We have discovered the barrier and potential seeds that occurred in cognitive dissonance during conceptualisation at the early stage of idea generation. The distinction of a creative individual is his/her ability to manage unfamiliar things, such as resources, making them become an advantage, instead of avoiding unfamiliar things. Gordon and his colleagues (1961) state making the familiar strange. It is a defamiliarisation process to have new resources, which we can use to think with and to go about changing our behaviour (Gordon; 1961). We are also reminded of Koestler's bisociation (1964), a term to illustrate the combinatorial nature of creativity to join unrelated, often conflicting, information in a new way (Koestler; 1964). Fauconnier and Turner's (2008) conceptual blending analyses how people combine perceptual, experiential and conceptual aspects of different concepts subconsciously to generate new insights (Fauconnier and Turner, 2008). The recent study of Nagai and Junaidy (2013) argues that the ability to capture and utilise stimuli during extreme levels of cognitive fixedness that produce conflicts of stimuli may lead to unconventional ways of thinking.

In the case of people with a traditional viewpoint, for example a craftsman, our study proves that weak conceptual stimulus exists as a challenge of unfamiliarity. This 
challenge is an unconventional resource which provides an opportunity to be exploited through targeted design education. Local government and design educators who create and deliver a design training need to be aware of these regional differences (cultural uniqueness) that exist as cognitive resources. The design educator must enable the craftsperson to identify and utilise these potential cognitive resources. This research aimed to establish the potential hidden in the barriers that can be used to improve the ability to enhance creative ideas and solutions. Therefore, through understanding the cultural uniqueness of these mindsets and stimuli we can provide resources for the development of design training (nationwide governmental HRD program in developing countries) that focus on the enhancement of traditional craftsmen's cognitive resources to produce more desirable products.

\section{Acknowledgements}

Acknowledgements are due to the Off-Campus Research Grant of Japan Advanced Institute of Science and Technology, to Buckinghamshire New University for providing technical support and all of the master craftsmen in UK and Indonesia involved in this research.

\section{References}

Adams, R.S. and Atman, C.J. (1999) 'Cognitive processes in iterative design behavior', in FIE'99. 29th Annual Frontiers in Education Conference, November, Vol. 1, pp.11A6-13, IEEE.

Adamson, G. (2007) Thinking Through Craft, Vol. 159, Berg, Oxford.

Beattie, S. (2009) Cottage Industries: Arts and Crafts in Donegal, Winthrop University, Rock Hill, S.C.

Blair, J. and Ramsay, N. (Eds.) (1991) English Medieval Industries: Craftsmen, Techniques, Products, Hambledon Press, London.

Cai, Y. (1993) Qing Dai Guang Shi JiaJu, p.66, 8 Dragons Publishing \& Cultural Services, Ltd., Hong Kong.

Cookson, A. and Ishimura, S. (2009) 'The early development of the English rattan seat: a comparison of Ming Dynasty Chinese seating and English rattan chairs, 1660-1700', デザイン学研究. 研究発表大会概要集, Vol. 56, pp.214-215.

Davison, G.C., Ralph, S.V. and Sandra, G.C. (1997) 'Think-aloud approaches to cognitive assessment and the articulated thoughts in simulated situations paradigm', Journal of Consulting and Clinical Psychology, Vol. 65, No. 6, p.950.

de Nooy, W., Mrvar, A. and Batagelj, V. (Eds.) (2005) Exploratory Social Network Analysis with Pajek, Vol. 27, University Press, Cambridge.

Fauconnier, G. and Turner, M. (2008) The Way We Think: Conceptual Blending and the Mind's Hidden Complexities, Basic Books, New York.

Finke, R.A. (1996) 'Imagery, creativity, and emergent structure', Consciousness and Cognition, Vol. 5, No. 3, pp.381-393.

Fitz Randolph, H.E., Hay, M.D. and Jones, A.M. (1978) The Rural Industries of England \& Wales: Decorative Crafts and Rural Potteries, EP Publishing, Wakefield.

Galey, J.C. (1981) 'The spirit of apprenticeship in a master craftsman', Contributions to Indian Sociology, Vol. 15, Nos. 1-2, pp.3-12. 
Georgiev, G.V. et al. (2012) 'Analysis of user feelings during interface operation: implications for creative design', DS 73-2 Proceedings of the 2nd International conference on Design Creativity, Vol. 2.

German, T.P. and Barrett, H.C. (2005) 'Functional fixedness in a technologically sparse culture', Psychological Science, Vol. 16, No. 1, pp.1-5.

Gero, J.S. (1999) 'Research methods for design science research: computational and cognitive approaches', Proceedings of ANZASCA.

Gero, J.S. (2011) 'Fixation and commitment while designing and its measurement', Journal of Creative Behavior, Vol. 45, No. 20, pp.108-115.

Glăveanu, V-P. (2011) 'How are we creative together? Comparing sociocognitive and sociocultural answers', Theory \& Psychology, Vol. 21, No. 4, pp.473-492.

Gordon, W.J. (1961) Synectics: The Development of Creative Capacity, Harper \& Row, New York.

Greenhalgh, P. (2002) The Persistence of Craft, Crafts Council, London.

Houtz, J.C. and Patricola, C. (1999) 'Imagery', in Runco, M.A. and Pritzker, S.R. (Eds.): Encyclopedia of Creativity, Vol. 2, pp.1-11, Academic Press, London.

Jansson, D. and Smith, S. (1991) 'Design fixation', Design Studies, Vol. 12, No. 1, pp.3-11.

Jonson, B. (2005) 'Design ideation: the conceptual sketch in the digital age', Design Studies, Vol. 26, No. 6, pp.613-624.

Junaidy, D.W. and Nagai, Y. (2013) 'The in-depth cognitive levels of imagination of artisans and designers', Journal of Design Research, Vol. 11, No. 4, pp.317-335.

Klamer, A. (2012) Crafting Culture: The Importance of Craftsmanship for the World of the Arts and the Economy at Large [online] http://www.klamer.nl/docs/crafting.pdf (accessed 28 March 2014).

Koestler, A. (1964) The Act of Creation, Hutchinsons, London.

Kotzé, P., Wong, W. and Jorge, J. (Eds.) (2008) Creativity and HCI: From Experience to Design in Education: Selected Contributions from HCIEd 2007, Vol. 289, 29-30 March 2007, Springer, Aveiro, Portugal.

Leach, B. (1972) Introduction to the Unknown Craftsman, Kodansha, Tokyo.

Martindale, C. (1995) 'Creativity and connectionism', in Steven, S.M., Ward, T.B. and Finke, R.F. (Ed.): The Creative Cognition Approach, pp.249-268, The MIT Press, Cambridge.

Nagai, Y. and Junaidy, D.W. (2013) 'Empowering cognitive fixedness', Proceedings of the 9th ACM Conference on Creativity \& Cognition, pp.291-294, ACM.

Pihlens, H. (2014) Rural Craft [online] http://www.hungerfordvirtualmuseum.co.uk/Themes/ Rural_Crafts/rural_crafts.html (accessed 20 April 2014).

Pye, D. (1968) The Nature and Art of Workmanship, UP, Cambridge.

Racz, I. (2009) Contemporary Crafts, Berg, Oxford.

Schön, D.A. (1983) The Reflective Practitioner: How Professionals Think in Action, Vol. 5126, Basic Books, New York.

Sennett, R. (2008) The Craftsman, University Press, Yale.

Solmsen, F. (1963) 'Nature as craftsman in Greek thought', Journal of the History of Ideas, Vol. 24, No. 4, pp.473-496.

Steadman, P. (2008) The Evolution of Designs: Biological Analogy in Architecture and the Applied Arts, Routledge, New York.

UN-REDD Programme (2009) The United Nations Collaborative Programme on Reducing Emissions from Deforestation and Forest Degradation in Developing Countries [online] http://www.un-redd.org/CountryActions/Indonesia/tabid/987/language/en-US/Default.aspx (accessed 20 April 20, 2014).

van Gompel, D., Hoving, J. and Klusener, R. (2013) Furniture from the Netherlands East Indies 1600-1900: A Historical Perspective Based on the Collection of the Tropenmuseum, KIT Publisher, Amsterdam. 
Viswanathan, V. and Linsey, J. (2012) 'A study on the role of expertise in design fixation and its mitigation', ASME 2012 International Design Engineering Technical Conferences and Computers and Information in Engineering Conference, pp.901-911.

Wiyancoko, D. (2002) 'Community-based industry in Indonesia: cultural identity or responsibility', Proceeding of International Symposium of PECC, Taiwan.

Yanagi, M. (1949) Folk Crafts in Japan, Kokusai Bunka Shinkokai, Tokyo.

Yanagi, M. (1989) The Unknown Craftsman: A Japanese Insight Into Beauty, Kodansha International, Tokyo. 